\title{
Cancer and Nutrition
}

National Cancer Institute

\section{Source}

National Cancer Institute. Cancer and Nutrition. NCI Thesaurus. Code C15658.

Systematic investigation into the role that nutrition plays in cancer. 